\title{
Simulation-based efficiency analysis of an in-plant milk-run operator under disturbances
}

\author{
Przemyslaw Korytkowski ${ }^{1} \cdot$ Rafal Karkoszka $^{1}$
}

Received: 31 January 2015 / Accepted: 12 June 2015 / Published online: 25 June 2015

(C) The Author(s) 2015. This article is published with open access at Springerlink.com

\begin{abstract}
This study examines the efficiency, interactions and impact of a milk-run operator on a typical assembly line. The idea behind the milk-run lies in organizing the material supply to production areas using a specialized logistic worker travelling in cycles between the warehouse and production. A discrete-event simulation model was developed to evaluate the interactions of the milk-run operator and a typical 10 workstation assembly line. We present an analysis of the various kinds of disturbances occurring in the production environment (time variability of technological operations and supply cycle, delays of supply cycles) and management decisions (takt time presence or absence, buffer capacity, supply cycle duration) on the production stability and performance (assembly line throughput rate, milk-run operator utilization, workstation starvation and work in process). Recommendations for designers of in-plant logistics are provided.
\end{abstract}

Keywords Milk-run · Simulation · Efficiency analysis ·

Throughput rate $\cdot$ In-plant logistics

\section{Introduction}

The arrangement of the material supply system within a plant has a significant impact on the performance of the manufacturing system [20]. Design of the manufacturing system should be performed together with design of the in-plant logistic system

Przemysław Korytkowski

pkorytkowski@zut.edu.pl

1 Faculty of Computer Science, West Pomeranian University of Technology, ul. Zolnierska 49, 71-210 Szczecin, Poland
[26] and external logistics [25]. Decisions about in-plant logistics have an impact on facility layout, buffer sizes, and work in process (WIP) [14]. In the competitive environment of manufacturing, elimination of the activities that do not add value to the products becomes more and more important. Material handling waste is one of Ohno's seven listed wastes [19]. Eliminating waste is the main principles of lean manufacturing [22]. A properly designed material handling system can lead to cost reduction from 10 to $30 \%$ [9]. The aim of the material handling systems is to maximize material availability while minimizing handling and storing costs, together with an increase in material handling vehicle usage rate, improved safety and working conditions and easing the manufacturing process [27].

The name "milk-run" originates from a milk selling system [3] where a milkman used to travel from door to door according to a specified repetitive itinerary replacing empty milk bottles with full ones. The milkman returns to the dairy after finishing his itinerary with a bunch of empty bottles. The next itinerary starts the following morning at the dairy where the empty bottles collected the previous day have been filled with fresh milk.

Translating this to a manufacturing environment, a milkrun operator (sometimes also called a milk runner) operates over a certain area providing all materials to several workstations according to a predefined itinerary. Figure 1 shows a simplified milk-run system. When designing milk-run logistics it is important to define the appropriate area covered by one milk runner and the optimal itinerary within the appointed area. These decisions affect the supply cycle time i.e. how long the itinerary takes, how much material should be carried and further, how much material should be in the input buffers at the workstations. The milk-run is applied to transport raw materials, waste, semi-finished and finished goods between manufacturing and assembly workstations and the warehouses [4]. 


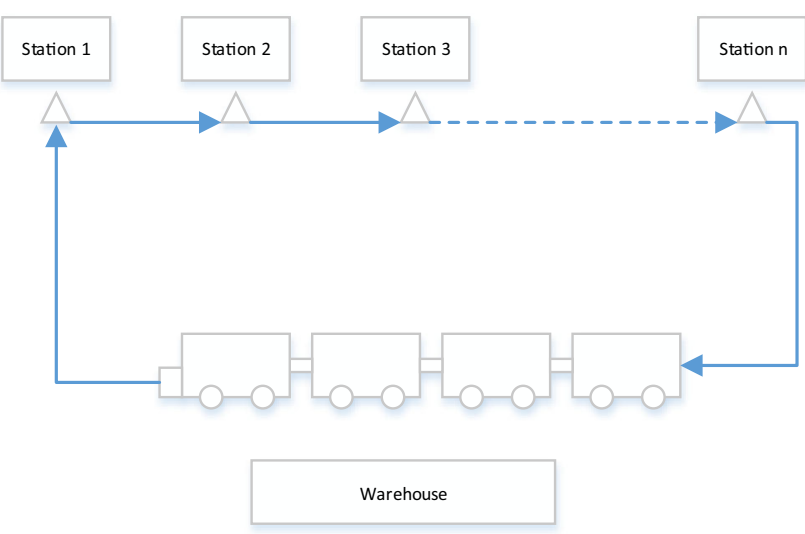

Fig. 1 In-plant milk-run system

Thanks to the milk-run, logistics performance is improved by effective usage of the transport vehicles, reduction of inventories and their maintenance costs, increases in delivery on-time, reductions of stock out at assembly lines, increased capital turnover and it establishes a good discipline in logistic operations (basis for standardization) [23].

The classic text on milk-run by Harris et al. [13] divides its implementation into five steps: (1) development of a plan for every part, (2) building of the purchased-parts market, (3) design delivery routes, (4) implement pull signals and (5) continuous improvement of the system (kaizen). The first step is gathering the necessary information about every part (materials and semi-finished parts) in the system to define the amount and frequency of deliveries. The second step is to build a supermarket by designing maximum inventory levels and rules for operating the market. Step concerns choosing the vehicle type, capacity, time period and itinerary. In the fourth step, the number of containers is determined. To sustain a milk-run in a good shape, standardization should follow the design step, supplemented by a small step by step improvement.

The sections of this paper are organized as follows. The following section summarizes relevant literature on in-plant material supply systems, with focus on milk-run. The third section describes a case study using a discrete-event simulation model of a typical assembly line with 10 workstations. The fourth section introduces various independent and dependent variables together with experimental design. The fifth section presents the results from the proposed experimental framework. Our conclusions and recommendations for designers of the in-plant logistics are presented in the final section.

\section{Literature review}

A short literature review of in-plant milk-run can be found in Kilic et al. [17]. Problems have been classified into three categories: (1) general assignment problems, (2) dedicated assignment problems and (3) determined time period assignment problems. In "general assignment problems", routes and time periods are not known. In "dedicated assignment problems", routes are known and time periods have yet to be determined. In "determined time period assignment problems", time periods are known but the problem is in determining the routes. The authors had concentrated on routes and time periods, and had not considered other types of decisions. As a result, it was concluded that it is more advantageous to use milk-run trains in the multiple routed vehicles method than a one routed vehicle method. Alnahhal and Noche [1] investigated the routing, scheduling and loading problems together in the milk-run tow train to decrease the number of trains, the variability in loading and route lengths and the inventory holding costs. In that study, they did not introduce any stochastic parameters and solve the problem using dynamic programming and mixed integer programming. They also assumed that kanban would not be used. Jafari-Eskandari et al. [15] investigated a dedicated assignment problem for an automotive supply chain with the objective function of minimizing the total cost of transportation and inventory costs using mixed integer programming.

A framework to design and manage the milk-run was proposed by Faccio et al. [11]. Here, the impacts of the long-term problems (kanban and fleet sizing) along with the short-term problems (fleet loading) are combined, providing optimal settings for the supermarket and management attributes.

A limited number of papers have been published regarding the relation between the efficiency and the detailed configuration of in-plant materials supply systems. A case study of a milk-run in-plant logistics implementation can be found in Domingo et al. [8]. The authors reported that thanks to implementation of the milk-run, intermediate warehouse stock was reduced by almost $50 \%$. Another in-plant milk-run case study can be found in Chee et al. [6]. Here, discrete-event simulation (Witness 2008 software) was used to compare the performance of two internal logistics systems: push and milk-run with kanban. Milk-run with kanban outperformed the push system. Throughput rate was higher, average waiting times and flow times were lower. In two papers, Bozer and Ciemnoczlowski [5, 7], analyzed the distribution of container locations and number of containers on the production system performance and probability of starvation. They found that increased vehicle capacity reduced the starvation probability to zero. Hanson and Finnsgård [12], with a case study about replacing both the forklifts with milk-run tow trains, and the pallets with plastic containers, reduced the work force at the assembly lines and inventory sizes beside the workstations. They also showed that more frequent deliveries do not cause milk-run operator utilization rates to grow in proportion. The optimization problem of a supermarket location (as a decentralized inventory) with tow trains used to feed 
workstation was analyzed by Alnahhal and Noche [2]. A genetic algorithm was developed to find an allocation with a minimal total transport and holding cost.

Many studies on milk-run supply systems consider the work as a scheduling, capacity or vehicle routing problem. Sadjadi et al. [23] developed a mixed integer mathematical model with a genetic algorithm for finding the optimal solution to all three problems mentioned above. Emde and Boysen [10] introduced a precise solution procedure based on nested dynamic programming of joint tow train routing and scheduling, together with a trade-off study between the number and capacity of the tow trains and the in-process inventory near the line. Satoglu and Sahin [24] developed a nonlinear mathematical model and heuristic approach entitled the Feasible Route Construction Algorithm where the routes are constructed and the service period is determined for the design of an internal milk-run material supply system. Kilic and Durmusoglu [16] praised the heuristic approaches for finding the optimum solution for in-plant logistics problems. Meta-heuristic algorithms such as the genetic algorithm, ant-colony optimization algorithm and simulated annealing algorithm can be applied.

None of these studies examined the milk-run operator, its behaviour in a production system, especially any delay in tour commencement and its impact on system efficiency. In this paper, with the use of a discrete-event simulation technique, we examine the efficiency, interactions and impact of a milkrun operator on a typical assembly line. The novelty in this article lies in the comprehensive analysis of disturbances occurring in the production environment (time variability of technological operations and supply cycle, delays of supply cycles) and management decisions (takt presence, buffer capacity, supply cycle duration). We propose a simulation-based experimental design to explore how those six factors affect four performance measures: assembly line throughput, milk-run operator utilization, workstation starvation and work in process. None of the existing studies has described the milk-run operator and its characteristics as a factor affecting the manufacturing system. Unique results from this approach are the recommendations for designers of in-plant logistics drawn from this study.

\section{Case study — assembly line}

In order to perform an efficiency analysis of an in-plant milkrun operator, we developed a case study of a typical assembly line. This assembly line is a close representation of a real-life line with only some simplifications of those manufacturing processes that were specific and would distort the results. We assume that a milk-run has already been established with a proper route and time design. In this case, one milk-run operator serves one assembly line. The operator has enough time to serve other lines but this is out of the scope of this study, as external actions could only cause delays to events relevant to the analyzed performance of the assembly line. Those external disturbances will be considered as independent parameters of the experimental design.

The assembly line consists of 10 workstations organized as a U-shaped one-piece flow production cell (see Fig. 2). The manufacturing process is organized in accordance to lean management principles. Operators at the assembly line are responsible only for performing technological operations. All raw materials are transported to the line and stored in containers. Containers are arranged in a proper order in front of each operator. The three bins system is implemented. Semifinished parts are conveyed between workstations automatically. The transfer time is $10 \mathrm{~s}$. Buffers between consecutive workstations have a finite capacity and a first-in-first-out queuing discipline. The speed of the milk-run operator is constant. The milk-run operator can carry an unlimited number of empty and full containers. No breakdowns occur during the milk-run tours.
Fig. 2 U-shaped manufacturing line

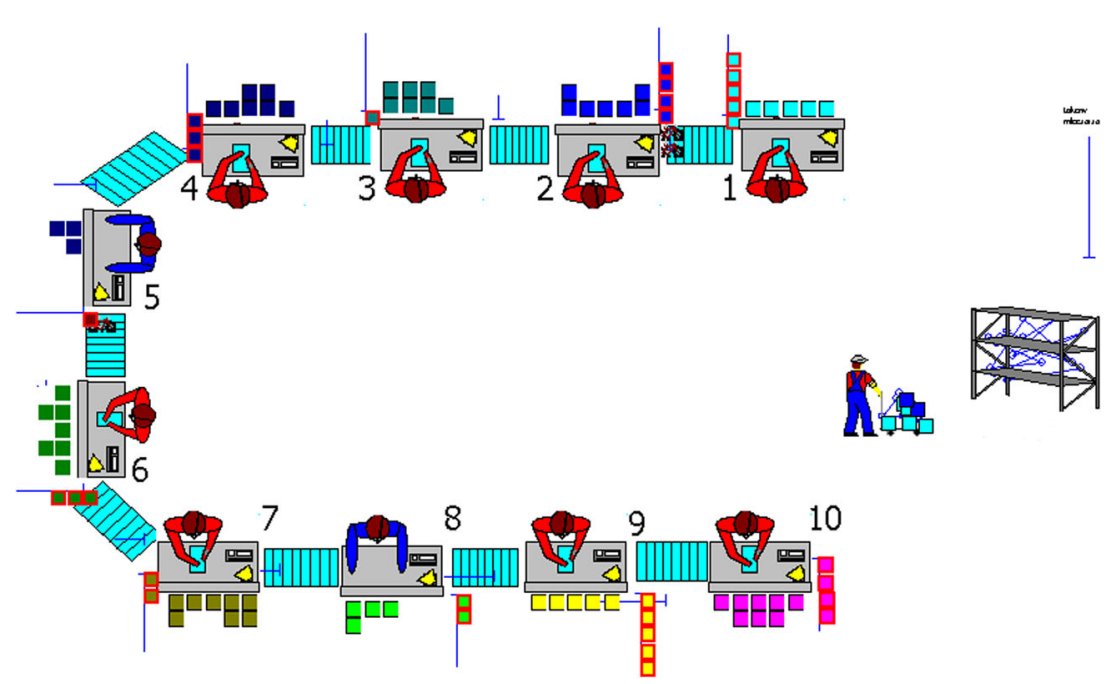


Table 1 Control parameters

\begin{tabular}{lll}
\hline Abbreviation & Factor & Factor levels \\
\hline TT & Takt time & Present (1), absent (0) \\
CV & Coefficient of variation & $0.05,0.15,0.30$ \\
BC & Buffer capacity & $1,3,5$ \\
CD & Cycle duration & Once per shift, twice per shift \\
DS & Delay of supply cycle start time & $0,0.2,0.5,1$ \\
DP & Delay probability & $0,0.1,0.3,0.5$ \\
\hline
\end{tabular}

To simplify analysis, the operation time at every workstation was set at the same value of $10 \mathrm{~min}$. Preliminary experiments have shown that this did not affect response parameters, because the workstation with the longest operational time will be the bottleneck determining the performance of the modelled assembly line. In addition, we introduced breakdowns to the line. Mean time between failures was set at 10 days exponentially distributed, and mean time to repair was set at $2 \mathrm{~h}$, also exponentially distributed.

The main focus in this article is the work of the milk-run operator. At the workstations, materials are stored in bins with a predefined capacity. The bin capacity was calculated on the basis of the quantity of pieces needed to complete the production plan within a specified period of time. This period of time has to be equal to cycle time of the milk-run operator tour. Each bin is labelled with information about stock keeping unit (SKU), storage position in the warehouse, consumption position (workstation ID) and capacity. A three-bin system is implemented. The first bin is the one from which the worker takes the parts for performing the technological operations. When that bin is empty, the worker puts it on a shelf with the other empty bins, and there it waits for the milk-run operator, which works as a kanban signal [18]. Then, the worker starts to take parts from the second bin. The third bin is en route to or from the warehouse where it is filled with a new set of parts. The milk-run operator start the tour itinerary at the

Table 2 Main effects and interactions for throughput rate

\begin{tabular}{llllrl}
\hline & Df & Sum Sq & Mean Sq & $F$ value & $P$ value \\
\hline TT & 1 & 6825 & 6825 & 1.7 & 0.1875 \\
CV & 2 & 2915205 & 1457603 & 371.8 & $<2.2 \mathrm{e}-16$ \\
BC & 2 & 2506278 & 1253139 & 319.6 & $<2.2 \mathrm{e}-16$ \\
CD & 1 & 627 & 627 & 0.2 & 0.6893 \\
DS & 3 & 6837367 & 2279122 & 581.3 & $<2.2 \mathrm{e}-16$ \\
DP & 2 & 3498305 & 1749153 & 446.1 & $<2.2 \mathrm{e}-16$ \\
CV:BC & 4 & 685062 & 171266 & 43.7 & $<2.2 \mathrm{e}-16$ \\
CD:DS & 3 & 30879 & 10293 & 2.6 & 0.0494 \\
CV:DP & 4 & 80441 & 20110 & 5.1 & 0.0004 \\
BC:DP & 4 & 73861 & 18465 & 4.7 & 0.0009 \\
DS:DP & 4 & 1036767 & 259192 & 66.1 & $<2.2 \mathrm{e}-16$ \\
TT:BC:DS & 6 & 51474 & 8579 & 2.1 & 0.0422 \\
\hline
\end{tabular}

warehouse by filling all empty bins collected during the previous tour. Then, the operator delivers the full bins to each workstation according to a predefined itinerary, while collecting the empty bins at each workstation. After visiting the last workstation, the operator returns to the warehouse, finishing the tour. This delivery system was designed with use of the framework proposed by Harris et al. [13].

The simulation model was built in Rockwell Automation Arena software. The simulation length was 60 working shifts of $8 \mathrm{~h}$. The warm-up period after preliminary experiments was set to three working shifts of $8 \mathrm{~h}$. All replications were computed with a different random number three times. Statistical analyses were performed in $\mathrm{R}$.

\section{Problem description and experimental design}

Our objective is to investigate the influence of the behaviour of the milk-run operator on the performance parameters of the production line. The ideal situation of everything going smoothly day-by-day does not frequently happen in many manufacturing environments. In this study, we have introduce several turbulences combined with system design decisions in

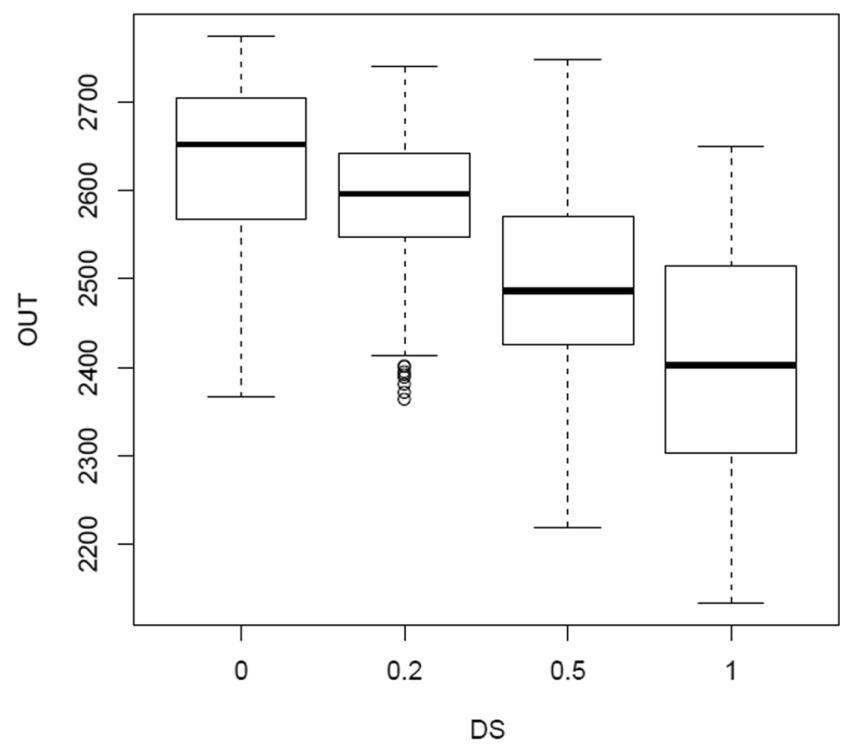

Fig. 3 Throughput rate (OUT) vs. delay of supply cycle start time (DS) 
Fig. 4 Throughput rate (OUT) vs. delay probability $(D P)$ and delay of supply cycle start time $(D S)$

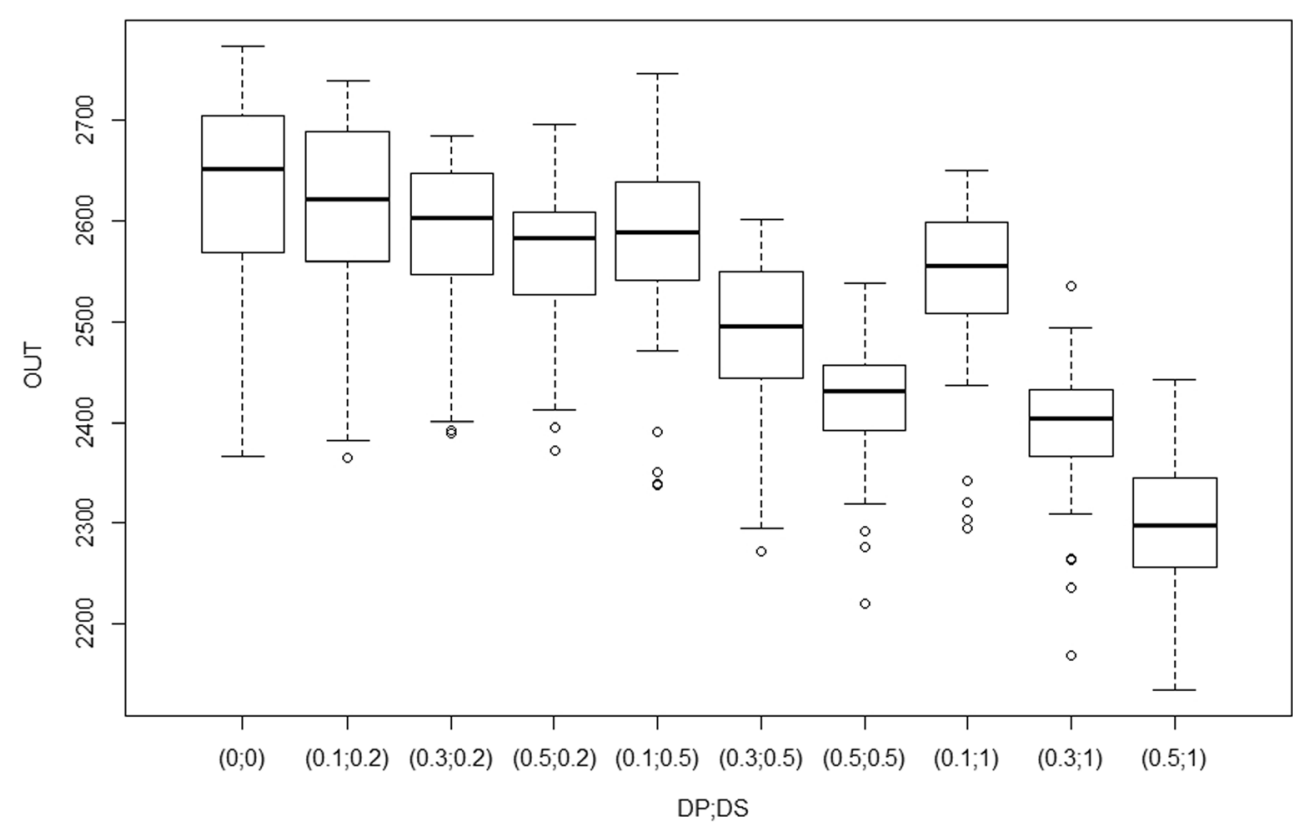

order to analyze the effects using six-way ANOVA. The question to be answered is whether they have any significant impact on performance measures like production capacity, work in progress, workstation starvation and milk-run operator utilization?

Three manufacturing system design decisions that we took into account are presence or absence of takt time, buffer capacity between workstations and milk-run operator cycle time. Another three decision parameters we treated as disturbances occurring at the assembly line are time variability of technological operations, time variability of the supply cycle and delays in supply cycle start. Below, we explain in detail all six decision parameters.

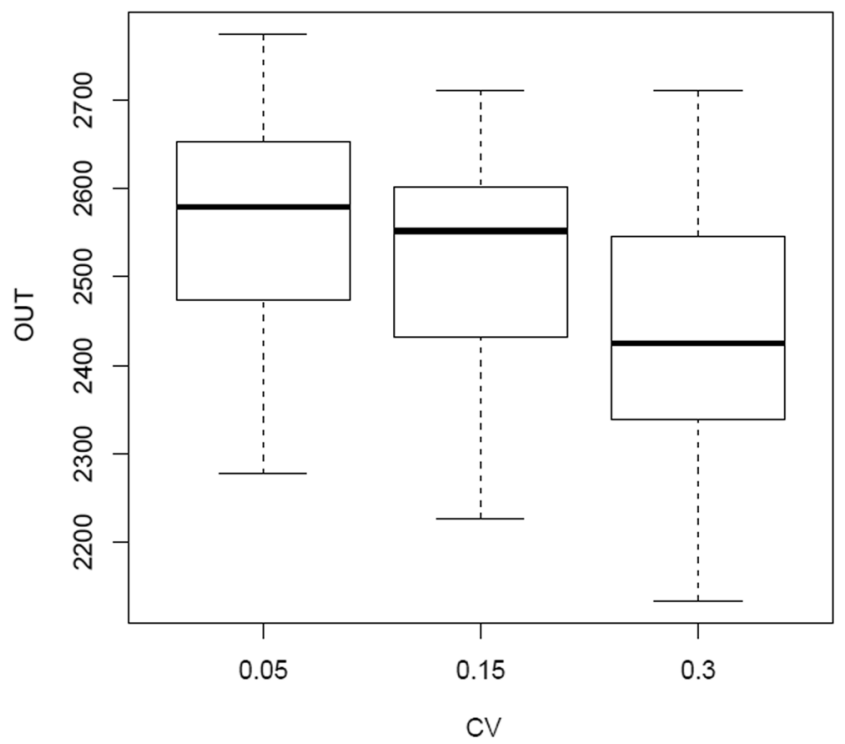

Fig. 5 Throughput rate $(O U T)$ vs. coefficient of variation $(C V)$
1) Takt time (TT) is used to synchronize the pace of production with the pace of sales [21]. If the cycle time (actual time to complete the tasks in a single job at a single workstation) is greater than takt time, the operation will be a bottleneck and additional time will be necessary to meet the production schedule. If the cycle time is less than takt time, there will be overproduction or waiting time, where the worker waits for the next takt time signal when he is ahead of schedule.

$\mathrm{TT}=\frac{T_{\mathrm{a}}}{D}$

where TT is takt time, $T_{\mathrm{a}}$ is the net time available to work per period, and $D$ is the customer demand per period. Takt time in the simulation model could be set active or

Table 3 Main effects and interactions for work in process

\begin{tabular}{lllrll}
\hline & Df & Sum Sq & Mean Sq & $F$ value & p value \\
\hline TT & 1 & 0 & 0.1 & 0 & 0.9205 \\
CV & 2 & 242 & 121.2 & 23.9 & $9.168 \mathrm{e}-11$ \\
BC & 2 & 47347 & 23673.5 & 4663.9 & $<2.2 \mathrm{e}-16$ \\
CD & 1 & 0 & 0.4 & 0.1 & 0.7924 \\
DS & 3 & 202 & 67.4 & 13.3 & $1.930 \mathrm{e}-08$ \\
DP & 2 & 79 & 39.3 & 7.7 & 0.0004 \\
CV:BC & 4 & 190 & 47.5 & 9.4 & $2.220 \mathrm{e}-07$ \\
CV:DS & 6 & 71 & 11.8 & 2.3 & 0.0318 \\
BC:DS & 6 & 127 & 21.1 & 4.2 & 0.0004 \\
BC:CD:DS & 6 & 79 & 13.2 & 2.6 & 0.0166 \\
TT:CD:DP & 2 & 46 & 22.9 & 4.5 & 0.0112 \\
BC:CD:DP & 4 & 68 & 17.1 & 3.4 & 0.0095 \\
TT:BC:CD:DP & 4 & 79 & 19.8 & 3.9 & 0.0038 \\
\hline
\end{tabular}


inactive. If takt time is active, the worker waits for the synchronization signal. If inactive, the worker starts a new task as soon as possible.

2) Buffers (BC) between workstations are set up with a firstin-first-out dispatching rule. The buffers in the whole assembly line have the same capacity. Here, buffer capacity (BC) could be 1,3 or 5 .

3) Milk-run cycle duration $(\mathrm{CD})$ determines how often the operator should begin the tour. In our case, the parameter is set to either 4 or $8 \mathrm{~h}$. Cycle duration determines the number of parts in each bin of the three-bin system. The longer the cycle time, the more parts in the bins and the milk-run operator spends more time in the warehouse filling the bins.

4) Managers are striving to minimize time variations in technological operations and the majority of studies cited in the literature review assume that this time is constant. Here, we investigate what happens when a time variation is present. We assume that the time to complete a task at a workstation is normally distributed $\mathrm{N}(\mu, \sigma)$ with a mean $\mu=10 \mathrm{~min}$. and a standard deviation expressed as the coefficient of variation $\sigma=\mu \times \mathrm{CV}$. The examined levels of the coefficient of variation are $0.05,0.15$ and 0.30 .

5) The delay of supply cycle start time (DS) represents all unforeseeable events occurring during the milk-run tour, which as a result affects the start time of the next cycle (tour). These events are for example longer times spent at the warehouse, various obstacles during the tour, breakdowns. We examined this factor in conjunction with the milk-run cycle duration $(\mathrm{CD})$ as its proportion. A delay factor of 0.5 means that the next milk-run cycle will be postponed by a half of the time of the whole cycle. We investigated cases with supply cycle start time delays of 0 , $0.2,0.5$ and 1 of the milk-run cycle duration.

6) Delay probability expresses how often a delay in the supply cycle start time happens. This factor was examined at levels of $0,0.1,0.3$ and 0.5

Summary information on the independent variables is presented in Table 1. There are two variables with two levels, two variables with three levels and two variables with four levels. The full mixed factorial experimental plan $2^{2} 3^{2} 4^{2}$ was designed with 360 scenarios to study. All combinations of control parameter levels were investigated. Combinations with either DS or delay probability (DP) equal to 0 were not investigated. Only experiments with both DP and DS equal to 0 , or both levels not equal to 0 , were simulated. For each scenario, three independent replications were simulated. The results from 1080 simulation runs were used in a multi-factor ANOVA.

The simulation experimental result was analyzed in four perspectives: assembly line throughput rate (OUT), milk-run operator utilization rate (U), workstation starvation (WS) and

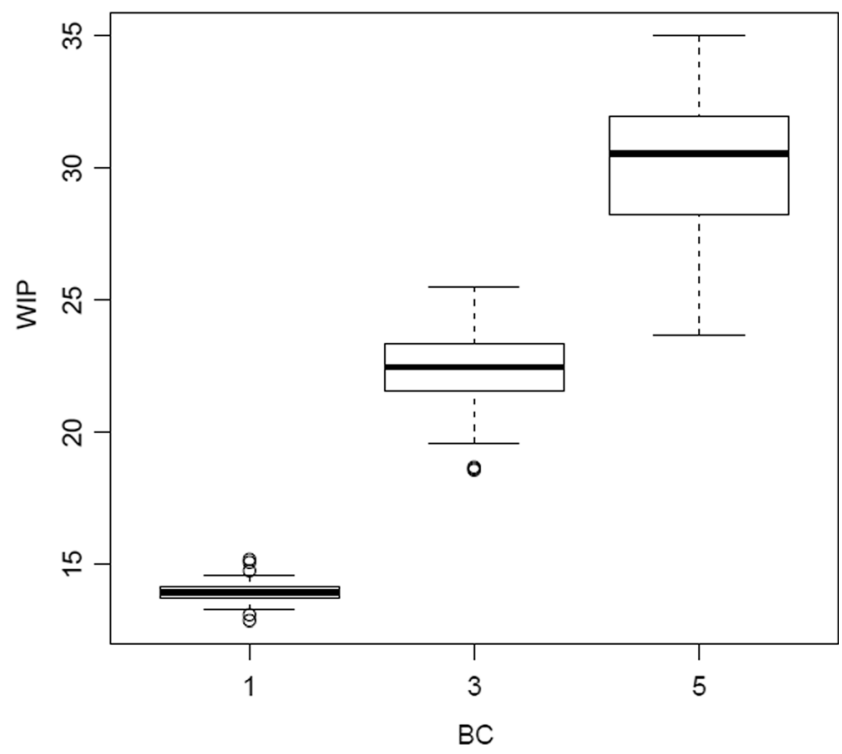

Fig. 6 Work in progress $(W I P)$ vs. buffer capacity $(B C)$

work in process (WIP) level. The simulation experimental results are analyzed using a six-way analysis of variance to examine the main effects and interactions of the factors.

\section{Experimental results and discussion}

The experimental results are presented in Tables 2 to 5, separated into the four dependent variables. Six-way ANOVA analysis was conducted at a $95 \%$ confidence level. Only significant $(P<0.05)$ factors and interactions are shown in the tables. The factor with the highest $F$ value and lowest $P$ value is considered as the factor most affecting the dependent variable. All statistical analyses were done in the $R$ environment.

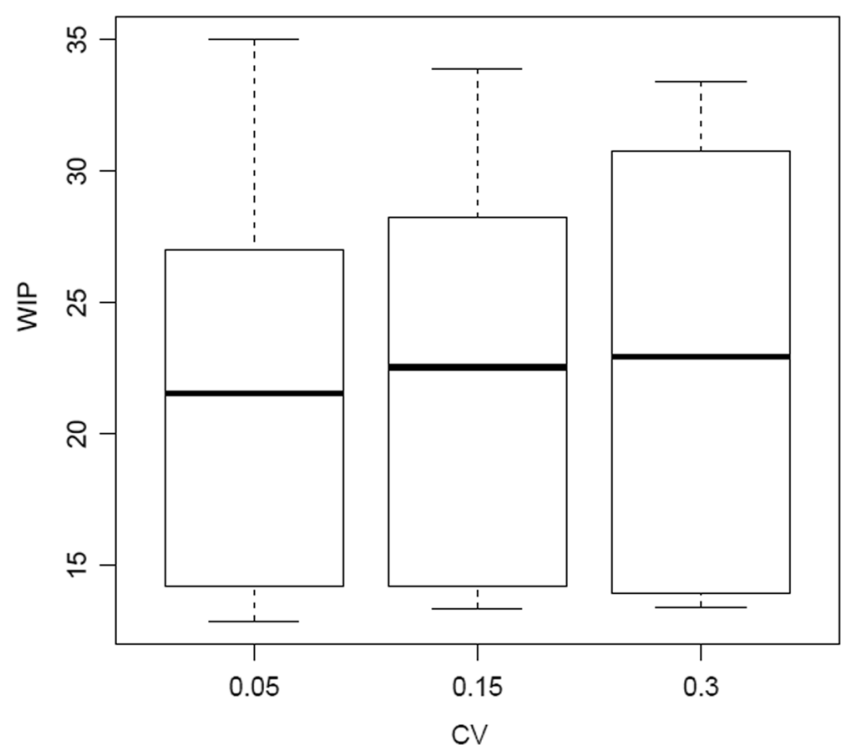

Fig. 7 Work in progress $(W I P)$ vs. coefficient of variation $(C V)$ 
Fig. 8 Workstation starvation $(W S)$ vs. delay of supply cycle start time $(D S)$ and delay probability $(D P)$

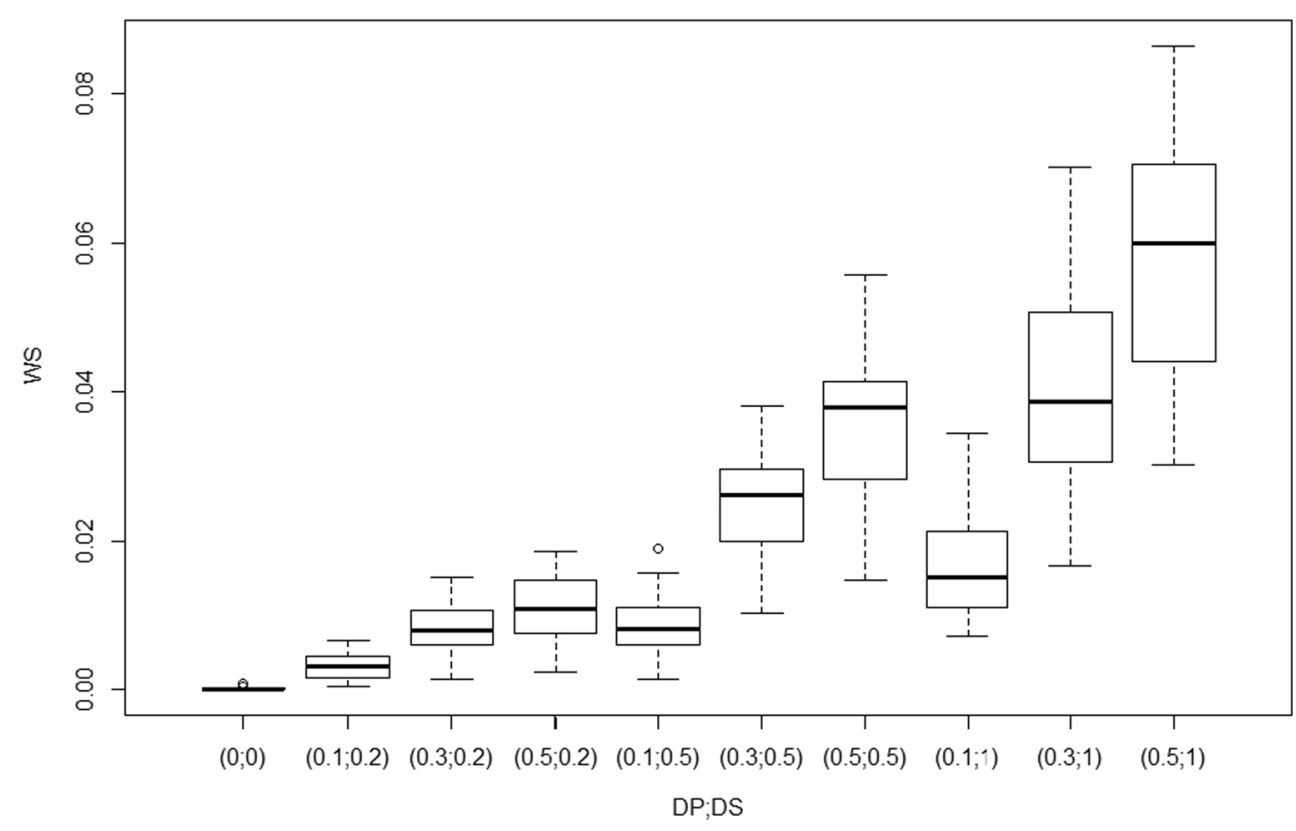

\subsection{Throughput rate}

The first analysis is the assembly line throughput rate (OUT). Table 2 presents the main effects together with two-way and three-way interactions. The maximum theoretical throughput rate of the assembly line is 6 products per hour, 48 per day and 2880 products over the simulation run horizon of 60 shifts.

Table 4 Main effects and interactions for workstation starvation

\begin{tabular}{llllll}
\hline & Df & Sum Sq & Mean Sq & $F$ value & $P$ value \\
\hline TT & 1 & 0.000060 & 0.000060 & 1.1 & 0.2876 \\
CV & 2 & 0.005220 & 0.002610 & 49 & $<2.2 \mathrm{e}-16$ \\
BC & 2 & 0.012455 & 0.006227 & 117 & $<2.2 \mathrm{e}-16$ \\
CD & 1 & 0.010600 & 0.010600 & 199.2 & $<2.2 \mathrm{e}-16$ \\
DS & 3 & 0.211447 & 0.070482 & 1324.5 & $<2.2 \mathrm{e}-16$ \\
DP & 2 & 0.106261 & 0.053130 & 998.4 & $<2.2 \mathrm{e}-16$ \\
CV:BC & 4 & 0.001269 & 0.000317 & 6 & 0.0001 \\
BC:CD & 2 & 0.000350 & 0.000175 & 3.3 & 0.0377 \\
CV:DS & 6 & 0.001315 & 0.000219 & 4.1 & 0.0004 \\
BC:DS & 6 & 0.004801 & 0.000800 & 15 & $2.947 \mathrm{e}-16$ \\
CD:DS & 3 & 0.005803 & 0.001934 & 36.4 & $<2.2 \mathrm{e}-16$ \\
CV:DP & 4 & 0.000709 & 0.000177 & 3.3 & 0.0102 \\
BC:DP & 4 & 0.002463 & 0.000616 & 11.6 & $4.118 \mathrm{e}-09$ \\
CD:DP & 2 & 0.001859 & 0.000929 & 17.5 & $3.918 \mathrm{e}-08$ \\
DS:DP & 4 & 0.031746 & 0.007937 & 149.1 & $<2.2 \mathrm{e}-16$ \\
TT:CV:BC & 4 & 0.000605 & 0.000151 & 2.8 & 0.0233 \\
TT:CV:DP & 4 & 0.000583 & 0.000146 & 2.7 & 0.0278 \\
CD:DS:DP & 4 & 0.001009 & 0.000252 & 4.7 & 0.0008 \\
TT:CV:BC:DP & 8 & 0.001172 & 0.000146 & 2.78 & 0.0053 \\
TT:CD:DS:DP & 4 & 0.000510 & 0.000128 & 2.4 & 0.0489 \\
TT:CV:BC:DS:DP & 16 & 0.001563 & 0.000098 & 1.8 & 0.0235 \\
\hline
\end{tabular}

The maximum observed throughput rate over all the experiments was 2816 and the minimum was 2071. ANOVA reveals that takt time and milk-run cycle duration do not influence the throughput rate.

The most affecting factor is the delay of supply cycle start time $(F=581 ; P<2.2 \mathrm{e}-16)$. The median output for $\mathrm{DS}=0$ is 2655 , and drops to 2397 for DS $=1$. Figure 3 shows that a big delay in milk-run operator cycle start decreases the throughput by approximately $10 \%$. Another parameter that has a big impact is delay probability $(F=446 ; P<2.2 \mathrm{e}-16)$. Frequent delays will reduce the throughput rate up to $15 \%$. It is quite obvious that interaction of these two parameters DS:DP is also significant $(F=66 ; P<2.2 \mathrm{e}-16)$. The explanation is straightforward as the first parameter defines how big the part delivery delay is, and the second defines how often this happens.

Table 5 Main effects and interactions for the milk-run operator utilization rate

\begin{tabular}{llllll}
\hline & Df & Sum Sq & Mean Sq & $F$ value & $P$ value \\
\hline TT & 1 & 0.00001 & 0.00001 & $3.2 \mathrm{e}+00$ & 0.0744 \\
CV & 2 & 0.00234 & 0.00117 & $3.7 \mathrm{e}+02$ & $<2.2 \mathrm{e}-16$ \\
BC & 2 & 0.00206 & 0.00103 & $3.2 \mathrm{e}+02$ & $<2.2 \mathrm{e}-16$ \\
CD & 1 & 0.51226 & 0.51226 & $1.6 \mathrm{e}+05$ & $<2.2 \mathrm{e}-16$ \\
DS & 3 & 0.00524 & 0.00175 & $5.5 \mathrm{e}+02$ & $<2.2 \mathrm{e}-16$ \\
DP & 2 & 0.00269 & 0.00134 & $4.2 \mathrm{e}+02$ & $<2.2 \mathrm{e}-16$ \\
CV:BC & 4 & 0.00052 & 0.00013 & $4.1 \mathrm{e}+01$ & $<2.2 \mathrm{e}-16$ \\
CD:DS & 3 & 0.00005 & 0.00002 & $5.6 \mathrm{e}+00$ & 0.0008 \\
CV:DP & 4 & 0.00006 & 0.00002 & $4.9 \mathrm{e}+00$ & 0.0006 \\
BC:DP & 4 & 0.00005 & 0.00001 & $4.2 \mathrm{e}+00$ & 0.0022 \\
DS:DP & 4 & 0.00080 & 0.00020 & $6.3 \mathrm{e}+01$ & $<2.2 \mathrm{e}-16$ \\
TT:BC:DS & 6 & 0.00004 & 0.00001 & $2.3 \mathrm{e}+00$ & 0.0341 \\
\hline
\end{tabular}




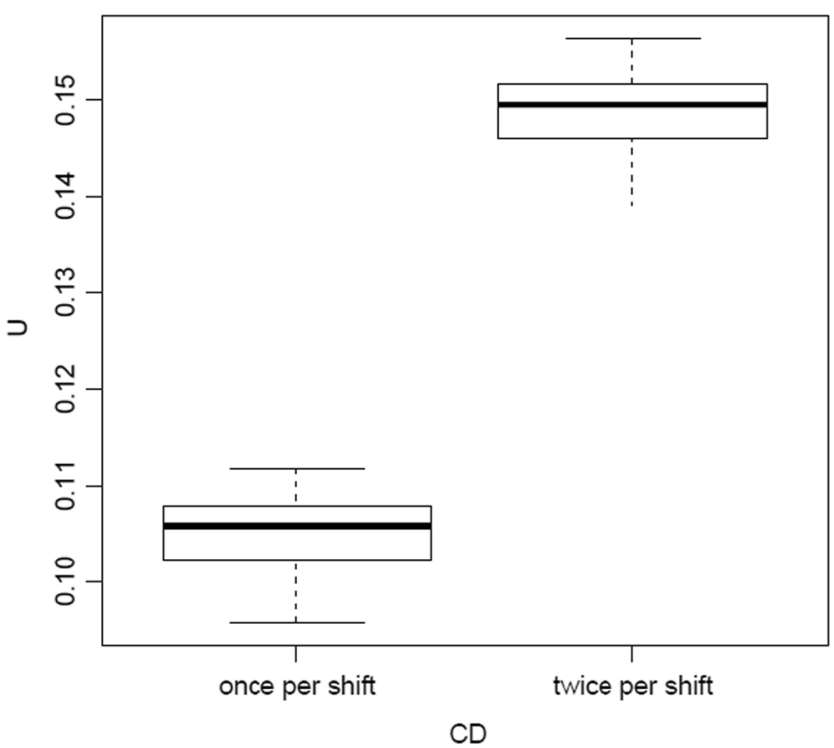

Fig. 9 Milk-run operator utilization rate $(U)$ vs. milk-run cycle duration $(C D)$

A breakdown of the delay of supply cycle start time together with the delay probability is presented on Fig. 4. Here, OUT values that are beyond the whiskers are due to a high CV. It can be noticed that the milk-run material delivery method is quite reliable, and even significant operator delays will not lower the throughput rate dramatically.

The third most important factor is the coefficient of variation $(F=371 ; P<2.2 \mathrm{e}-16)$. Figure 5 shows the impact of this factor on the throughput rate. A higher variance in processing times causes the system to be less stable and less capable of producing smaller amount of goods. However, even the highest $\mathrm{CV}=0.3$ reduces production by just $6 \%$. Buffer capacity $(F=319 ; P<2.2 \mathrm{e}-16)$ is also statistically important but a small buffer only reduces median production by just $6 \%$.

\subsection{Work in process}

Work in progress (WIP) is calculated as the sum of all semifinished products excluding parts (materials) stored in bins at every workstation. Table 3 presents the results of a six-way ANOVA of the main effects and up to four-way interactions. Here again, takt time and cycle duration are not statistically important. Only buffer capacity has an impact on work in progress with a more than two orders of magnitude higher value of $F=4664$ and $P<2.2 \mathrm{e}-16$. This is typical for any assembly line, not only for those with a milk-run delivery. Median WIP values (Fig. 6) grow from about 14 for a small buffer to over 30 for a buffer with a capacity of 5 products.

The rest of the parameters, although statistically significant, influence work in progress minimally. For example, analyzing the coefficient of variation $F=24$ with $P=9.168 \mathrm{e}-11$ reveals that increasing CV (see Figs. 7) from 0.05 to 0.3 , the WIP median increases from 21.5 to 23 , which is just $6 \%$.

\subsection{Workstation starvation}

Workstation starvation (WS) occurs when a worker has to stop work due to a lack of materials in the bins. This parameter is calculated as the ratio of time when the necessary parts were unavailable on the workstations to the total available working time

$\mathrm{LP}=\frac{\sum_{i} t_{\mathrm{u}}}{\sum_{i} t_{\mathrm{a}}}$

where $i$ is the workstation number, $t_{u}$ is the time when parts were unavailable on the $i$-th workstation and $t_{a}$ is the available working time.
Fig. 10 Milk-run utilization rate $(U)$ vs. delay of supply cycle start time $(D S)$ and delay probability $(D P)$

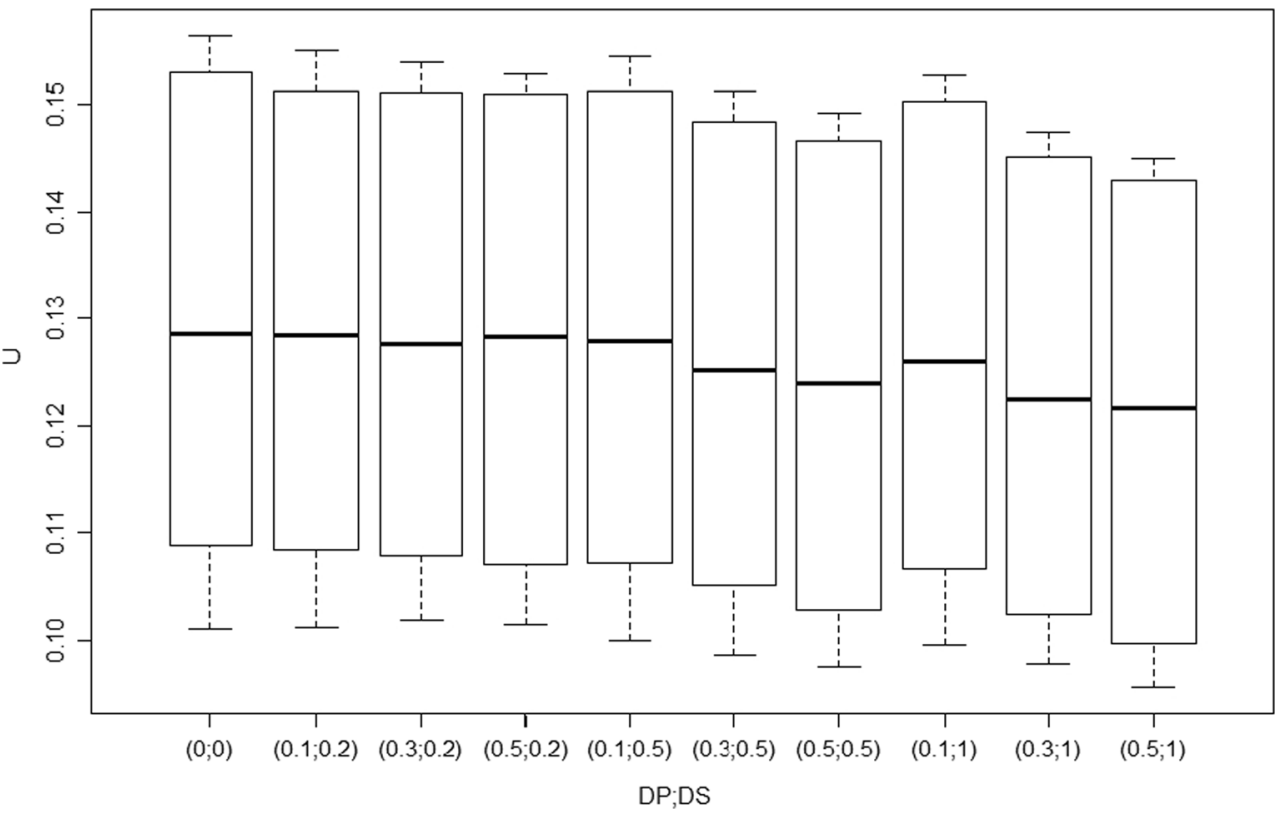


Table 6 All results: averages with half width at $95 \%$ confidence level

\begin{tabular}{|c|c|c|c|c|c|}
\hline & & $\begin{array}{l}\text { Throughput rate } \\
\text { (OUT) }\end{array}$ & $\begin{array}{l}\text { Work in process } \\
\text { (WIP) }\end{array}$ & $\begin{array}{l}\text { Milk-run operator } \\
\text { utilization rate }(U)\end{array}$ & $\begin{array}{l}\text { Workstation } \\
\text { starvation (WS) }\end{array}$ \\
\hline \multirow[t]{2}{*}{ Takt time (TT) } & Present & $2509 \pm 6$ & $22.2 \pm 0.3$ & $0.127 \pm 0.001$ & $0.02 \pm 0.001$ \\
\hline & Absent & $2504 \pm 6$ & $22.2 \pm 0.3$ & $0.127 \pm 0.001$ & $0.021 \pm 0.001$ \\
\hline \multirow[t]{3}{*}{ Buffer capacity (BC) } & 1 & $2441 \pm 7$ & $14.0 \pm 0.1$ & $0.125 \pm 0.001$ & $0.016 \pm 0.001$ \\
\hline & 3 & $2524 \pm 7$ & $22.4 \pm 0.1$ & $0.127 \pm 0.001$ & $0.021 \pm 0.001$ \\
\hline & 5 & $2554 \pm 7$ & $30.2 \pm 0.2$ & $0.128 \pm 0.001$ & $0.024 \pm 0.001$ \\
\hline \multirow[t]{2}{*}{ Cycle duration (CD) } & Once per shift & $2506 \pm 6$ & $22.2 \pm 0.3$ & $0.105 \pm 0.0001$ & $0.018 \pm 0.001$ \\
\hline & Twice per shift & $2507 \pm 6$ & $22.2 \pm 0.3$ & $0.149 \pm 0.0001$ & $0.024 \pm 0.001$ \\
\hline \multirow[t]{3}{*}{ Coefficient of variation (CV) } & 0.05 & $2563 \pm 7$ & $21.6 \pm 0.4$ & $0.129 \pm 0.001$ & $0.029 \pm 0.001$ \\
\hline & 0.15 & $2520 \pm 7$ & $22.3 \pm 0.4$ & $0.127 \pm 0.001$ & $0.021 \pm 0.001$ \\
\hline & 0.3 & $2437 \pm 7$ & $22.7 \pm 0.4$ & $0.125 \pm 0.001$ & $0.018 \pm 0.001$ \\
\hline \multirow[t]{4}{*}{ Delay of supply cycle start time (DS) } & 0 & $2626 \pm 7$ & $22.9 \pm 0.4$ & $0.130 \pm 0.001$ & $0.0001 \pm 0.00001$ \\
\hline & 0.2 & $2583 \pm 6$ & $22.6 \pm 0.4$ & $0.129 \pm 0.001$ & $0.007 \pm 0.0003$ \\
\hline & 0.5 & $2492 \pm 7$ & $22.0 \pm 0.4$ & $0.127 \pm 0.001$ & $0.023 \pm 0.0009$ \\
\hline & 1 & $2405 \pm 6$ & $21.7 \pm 0.4$ & $0.124 \pm 0.001$ & $0.039 \pm 0.0014$ \\
\hline \multirow[t]{4}{*}{ Delay probability (DP) } & 0 & $2626 \pm 14$ & $22.9 \pm 0.4$ & $0.130 \pm 0.001$ & $0.0001 \pm 0.00001$ \\
\hline & 0.1 & $2571 \pm 14$ & $22.5 \pm 0.4$ & $0.129 \pm 0.001$ & $0.009 \pm 0.001$ \\
\hline & 0.3 & $2484 \pm 15$ & $21.9 \pm 0.4$ & $0.126 \pm 0.001$ & $0.025 \pm 0.001$ \\
\hline & 0.5 & $2425 \pm 17$ & $21.8 \pm 0.4$ & $0.125 \pm 0.001$ & $0.035 \pm 0.001$ \\
\hline
\end{tabular}

Table 4 presents the main factors and up to five-way interactions. All factors, except takt time, have an impact on workstation starvation with a probability $P<2.2 \mathrm{e}-16$. Workstation starvation is the factor which is affected by the greatest number of factors and interactions. Again, the delay of milk-run operator cycle start and delay probability have the highest impact with, respectively, $F=1324$ and $F=998$. Their two-way interaction is also significant at $F=149$.

Increases in the delay of milk-run operator cycle start (DS) and delay probability (DT) result in greater workstation starvation (see Fig. 8). A milk-run tour delayed for 0.2 of its length will increase workstation starvation by about 0.02 . This small change in starvation can imply significant changes in throughput rate in the occurrence of unfavourable circumstances like a low buffer capacity and a high coefficient of variation. If $\mathrm{BC}=1$ then when one workstation stops due to a parts shortage, almost immediately all others workstations stop too. A high buffer capacity could only sustain production for a limited time. The median of workstation starvation is about 0.06 when the delay of supply cycle start time and delay probability are at their highest levels. This causes the median of OUT to drop by approx $15 \%$. This shows that even frequent and long delays do not dramatically increase workstation starvation and as a consequence do not significantly reduce throughput rate. However, all planned milk-run tours must be completed, no matter how long the delay is.

\subsection{Milk-run operator utilization rate (U)}

The milk-run operator can be assigned to one long route or several shorter routes. In our case, we assume that our assembly line is just one of the lines served by the operator. Here, we analyze how much of the working shift time the operator spends supplying the assembly line. As it was stated in section 3, we are not interested in what the milk-run operator does during the rest of the time, thus the utilization rate $(U)$ is rather small as it is calculated in relation to the duration of the entire shift. It is obvious that one tour per shift takes less than two tours. This can be seen from the ANOVA results where cycle duration (CD) is the most significant factor with $F=160810$ and $P<2.2 \mathrm{e}-16$ (see Table 5 and Fig. 9). It is quite interesting how other parameters affect the time needed for serving (directly translating into utilization rate) the assembly line by the milk-run operator.

Almost all factors except takt time are statistically important for the utilization rate; the same is for many two-way interactions. $F$ values are quite high and $P$ values are small. Let us have a closer look at two factors that were already studied in detail in the previous sections and are closely related to the performance of the milk-run operator, i.e. delay of supply cycle start time (DS) and delay probability (DP). For both factors, changes of their levels translate into changes in the operator utilization rate. But when we analyze Figure 10, it can be seen that the change is in reality quite insignificant as 
the median values are between 0.12 and 0.13 . This is a minor change for the process planners.

\section{Discussion and conclusions}

Let us summarize the results from the previous section and try to develop recommendations for managers and industrial engineers who are responsible for seamless production. In this study, with the use of a discrete-event simulation technique, we explored the interaction of the milk-run operator with an assembly line organized in accordance with good lean management practice. The supply of materials was carried out using a three-bin method. The parameters of the assembly line simulation model were selected carefully, mainly with a view to highlighting the impact of the operator actions and not the line as such. For this reason, the durations of the technological operations on all workstations were the same. This is quite unrealistic, but if we assume that these times varied and as a result some workers had some idle time, the results of the study would be blurred. For example, some buffers would build up without a connection to the milk-run operator actions.

The research question was if and how much disturbances occurring in the production environment (time variability of technological operations and supply cycle, delays of supply cycles) and management decisions (takt presence, buffer capacity, supply cycle duration) affect operations at a typical assembly line. Results of the simulation study are presented in Table 6. Results are presented for four analyzed performance measures versus six control parameters.

First, let us have a closer look at management decisions. In our case of a well-balanced assembly line, the presence or absence of takt time (TT) did not affect the line. It is straightforward that increasing buffer capacity leads to greater work in progress. But when looking at it from the other side, a milkrun with three bins allows for a reasonably safe limiting of the size of buffers. We have examined configurations with a very small buffer capacity of 1 , with and without takt time synchronization, where one could expect that milk-run operator problems would be directly transferred to the production line. No such situation happens. This is because the milk-run delivery system stabilizes the quantity of materials in circulation and there is an assurance that there are almost always parts in one of the three bins available for the worker. Decisions about the frequency of milk runner visits can be considered taking into account just workstation starvation probability, as it neither affected throughput rate nor work in progress. Lengthening the cycle duration leads to lower milk runner utilization, giving him more time to handle materials to other production areas but at the cost of higher line-side inventory levels.

Secondly, let us analyze how big an influence on the assembly line disturbances have. One important managerial problem is variation in the technological operation time duration. It is not surprising then that as the coefficient of variation increases, the performance of the line diminishes. Milk-run with three bins reduces the impact of variations. At the same time, workstation starvation drops by one third because the line production rate falls, i.e. demand for material is lower, and material supply is unaffected. Even more interesting results are obtained in investigating what happens when the milk runner cycle is delayed because of external problems. Even a severe situation, when the start time is delayed by one full delivery cycle, and with it happening on average every second cycle, does not bother the line as much as one would expect.

The most important outcome of the research is that the milk-run system is a very stable supply of parts to the production line. The experimental design we created included quite severe disturbances. The analysis conducted showed that the milk-run system was able to recover very quickly from even big problems like long and frequent delays in parts delivery. In extreme cases, the throughput rate dropped at most $15 \%$. In many cases, smaller disturbances had almost no effect on the performance of the assembly line.

Another conclusion that could be drawn from this study is that the workload of a milk-run operator could be very high. Analysis shows that there is no need to leave any kind of safety time, as any unforeseen disturbances causing delays will be compensated rapidly.

Open Access This article is distributed under the terms of the Creative Commons Attribution 4.0 International License (http:// creativecommons.org/licenses/by/4.0/), which permits unrestricted use, distribution, and reproduction in any medium, provided you give appropriate credit to the original author(s) and the source, provide a link to the Creative Commons license, and indicate if changes were made.

\section{References}

1. Alnahhal M, Noche B (2013) Efficient material flow in mixed model assembly lines. Springer Plus 2(1):415

2. Alnahhal M, Noche B (2015) A genetic algorithm for supermarket location problem. Assem Autom 35(1):122-127

3. Alnahhal M, Ridwan A, Noche B (2014) In-plant milk run decision problems. In: 2014 International Conference on Logistics Operations Management., pp 85-92

4. Baudin M. (2005). Lean logistics: the nuts and bolts of delivering materials and goods. New York Productivity Press

5. Bozer YA, Ciemnoczolowski DD (2013) Performance evaluation of small-batch container delivery systems used in lean manufacturing - Part 1: system stability and distribution of container starts. Int J Prod Res 51(2):555-567

6. Chee SL, Yong M, Chin JF (2012) Milk-run kanban system for raw printed circuit board withdrawal to surface-mounted equipment. J Ind Eng Manag 5(2):382-405

7. Ciemnoczolowski DD, Bozer Y (2012) Performance evaluation of small-batch container delivery systems used in lean manufacturing - Part 2: number of kanban and workstation starvation. Int $\mathrm{J}$ Prod Res 51(2):1-14 
8. Domingo R, Alvarez R, Peña MM, Calvo R (2007) Materials flow improvement in a lean assembly line: a case study. Assem Autom 27(2):141-147

9. Drira A, Pierreval H, Hajri-Gabouj S (2007) Facility layout problems: a survey. Annu Rev Control 31(2):255-267

10. Emde S, Boysen N (2012) Optimally routing and scheduling tow trains for JIT-supply of mixed-model assembly lines. Eur J Oper Res 217(2):287-299

11. Faccio M, Gamberi M, Persona A, Regattieri A, Sgarbossa F (2013) Design and simulation of assembly line feeding systems in the automotive sector using supermarket, kanbans and tow trains: a general framework. J Manag Control 24(2):187-208

12. Hanson R, Finnsgård C (2014) Impact of unit load size on in-plant materials supply efficiency. Int J Prod Econ 147:46-52

13. Harris R, Harris C, Wilson E, Womack J (2010) Making materials flow: a lean material-handling guide for operations, productioncontrol and engineering professionals. The Lean Enterprise Institute, Cambridge

14. Hiregoudar C, Reddy BR (2007) Facility planning \& layout design: an industrial perspective. Technical Publications Pune, Pune

15. Jafari-Eskandari M, Sadjadi SJ, Jabalameli MS, Bozorgi-Amiri A (2009) A robust optimization approach for the Milk Run problem (An auto industry Supply Chain Case Study). In International conference on computers and industrial engineering. CIE 2009 pp. 1076-1081

16. Kilic HS, Durmusoglu MB (2013) A mathematical model and a heuristic approach for periodic material delivery in lean production environment. Int J Adv Manuf Technol 69:977-992
17. Kilic HS, Durmusoglu MB, Baskak M (2012) Classification and modeling for in-plant milk-run distribution systems. Int J Adv Manuf Technol 62(9-12):1135-1146

18. Liker JK, Meier D (2006) Toyota way fieldbook. McGraw-Hill, New York

19. Ohno T (1988) Toyota production system: beyond large-scale production. Productivity Press, Cambridge

20. Rother T (2011) Per Milkrun und Routenzugsystem Leerfahrten deutlich verringern, Maschinen Markt 51/52

21. Rother M, Harris R (2001) Creating continuous flow: an action guide for managers engineers and production associates. The Lean Enterprise Institute, Cambridge

22. Rother M, Shook J (2003) Learning to see: value-stream mapping to create value and eliminate muda. The Lean Enterprise Intitute, Cambridge

23. Sadjadi SJ, Jafari M, Amini T (2008) A new mathematical modeling and a genetic algorithm search for milk run problem (an auto industry supply chain case study). Int J Adv Manuf Technol 44(12):194-200

24. Satoglu SI, Sahin IE (2013) Design of a just-in-time periodic material supply system for the assembly lines and an application in electronics industry. Int J Adv Manuf Technol 65(1-4): 319-332

25. Sitek P.. \& J. Wikarek (2015). A hybrid approach to the optimization of multiechelon systems. Mathematical Problems in Engineering. vol. 2015. Article ID 925675

26. Stephens MP, Meyers FE (2010) Manufacturing facilities: design \& material handling. Upper Saddle River, Pearson

27. Sule D (1994) Manufacturing facilities. PWS Publishing Company, Boston 